\title{
Transesterification of waste frying oil under ultrasonic irradiation
}

\author{
Ángeles Cancela ${ }^{1}$, Rocío Maceiras ${ }^{2}$, Víctor Alfonsín ${ }^{2}$, Ángel Sánchez ${ }^{1}$
}

\begin{abstract}
This study investigates the effect of ultrasounds in conversion of waste frying oil into biodiesel. Many researchers have studied the use of ultrasounds in the biodiesel production from different feedstock; however, there are few studies focused on the biodiesel production from waste frying oil. In this research, ultrasound-assisted transesterification was carried out to convert the waste frying oil into biodiesel directly. The effect of different process parameters such as reaction time (30-90 min), amount of catalyst $(0.5-1 \%$ wt. $\mathrm{NaOH})$ and temperature $\left(20-40{ }^{\circ} \mathrm{C}\right)$ were also analyzed to obtain the higher conversion. A methanol to oil molar ratio of $6: 1,0.5 \%$ amount of catalyst and $30{ }^{\circ} \mathrm{C}$ was enough to complete the process in $60 \mathrm{~min}$. The obtained results in this study confirm that that ultrasound-assisted transesterification was a fast and efficient method for biodiesel production from waste frying oil even if reaction temperature is low.
\end{abstract}

Keywords: ultrasound transesterification, waste frying oil, biodiesel.

\section{Introduction}

The use of waste frying oil for biodiesel production has gained interest in the last years. This is mainly due to the fact that it is a household waste that is usually poured dawn the drain causing environmental hazards or it is collected to be properly treated and disposed. It is estimated that among 1.85 and 2.65 millions are collected in Europe by day (Gude and Grant, 2013). For that reason, different researches have tried to use this waste for different purposes, such as soap production (Wijana et al., 2005), thermal cracking (Zaher, 2003) and more recently to obtain alternative fuel, biodiesel (Felizardo et al., 2006).

Biodiesel is obtained by transesterification of vegetable oils and animal fats with an alcohol in presence of a catalyst (Fukuda et al., 2001). The transesterification reaction takes place between a lipid and an alcohol to produce an ester and a by-product, glycerol, also known as glycerine. This reaction occurs stepwise, with mono and diglycerides as intermediate products. The obtained fuel performs in a similar way to petroleum-derived fuel and presents some advantages, such as: (i) it reduces greenhouse emissions because it is a renewable resource (Dorado et al., 2003; Ulusoy et al., 2004); (ii) it is biodegradable; (iii) its combustion products have reduced levels of particulates, carbon monoxide and nitrogen oxides (Mittelbach and Tritthart, 1988; Schafer, 1998).

Biodiesel can be obtained from a variety of different raw materials and many researches have analysed the better conditions to obtain this biofuel (Refaat et al., 2008; Phan and Phan, 2008; Maceiras et al., 2009). However, one of the most critical aspects remains the raw material costs and its limited availability. The problem that presents the majority of raw materials for biodiesel production is the use of land for production of oil for biodiesel feedstock competes with the use of land for food production. With the consequent increase of the price of edible plant and vegetable oils. Then, the use of waste cooking oil as biodiesel feedstock could be a good alternative to the industry.

Recently, the application of ultrasonic irradiation has been used to improve the transesterification 
process (Yu et al., 2010; Thanh, et al., 2010) since it reduces the reaction time and improve the mass transfer between the immiscible liquid phases (Ehimen et al., 2012). It has been reported (Stavarache et al., 2005) that the oil-methanol phase is distupted due to the collapse of ultrasonically induced cavitation bubbles, in turn leading to an accelerated alkyl ester formation. In this study, the basic transesterification of waste frying oil was carried out under ultrasonic irradiation. Process parameters such as catalyst amount, reaction time and temperature were studied with the aim to obtain the better conditions.

\section{Materials and methods}

\subsection{Materials}

Waste frying oil used in this paper was obtained from a local restaurant (Pontevedra, Spain). Waste frying oil was filtered under vacuum and dried, prior to use. Methanol was used as transesterification agent, and $\mathrm{NaOH}$ as alkaline catalyst. All the reagents used during synthesis and characterization procedures were obtained commercially and are of analytical grade.

\subsection{Ultrasonic irradiation unit}

Ultrasound bath (Model S 300H from Elmasonic with power rating of 300W and frequency of irradiation of $37 \mathrm{kHz}$ ) was used as the source of ultrasonic irradiation to carry out the transesterification reaction. The equipment allows to set the temperature of the bath between 30 and $80^{\circ} \mathrm{C}$.

\subsection{Experimental procedure}

The scheme of the experimental procedure is shown in figure 1. The transesterification reaction was carried out in a $500 \mathrm{~mL}$ spherical batch reactor, provided with a thermometer, within a ultrasound bath. The volume of the oil was fixed at $300 \mathrm{~mL}$ for all experiments and the methanol to oil molar ratio was 6:1 in all cases. Different amounts of sodium hydroxide $(0.5$ and $1 \% \mathrm{wt} / \mathrm{wt}$ ) were dissolved in the methanol and the solution was added to the reactor when the initial temperature of the oil was reached. Initial temperature was varied from 20 to $40{ }^{\circ} \mathrm{C}$ by increments of $10^{\circ} \mathrm{C}$. The reaction was carried out at different reaction times (30, 60 and $\left.90 \mathrm{~min}\right)$. After the ultrasound-assisted transesterification, the reaction mixture was settled to separate the biodiesel to the glycerol. The resultant product was washed twice to ensure the complete removal of unreacted methanol and byproducts. Finally, the fatty acid methyl esters and acidity value of obtained biodiesel was analysed.

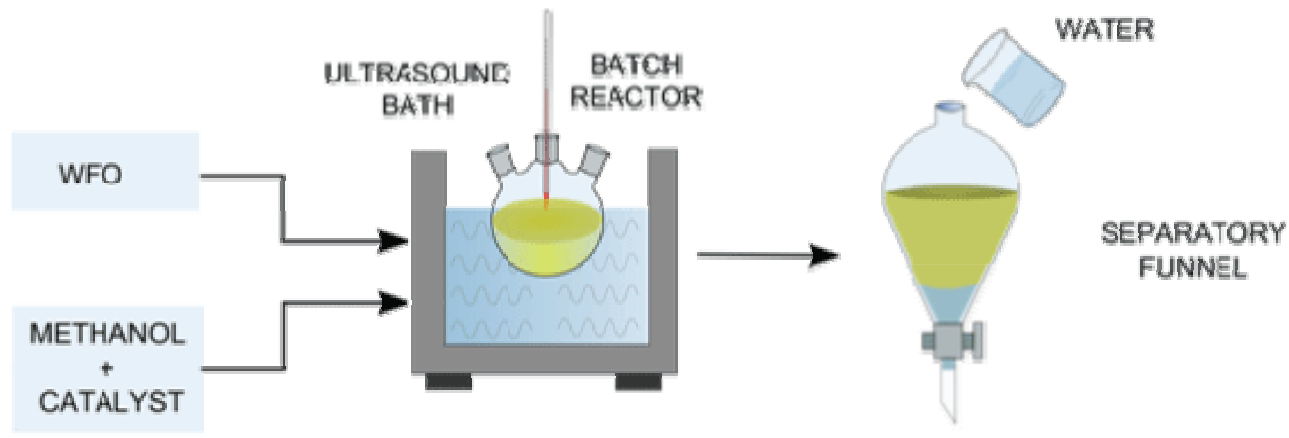

Figure 1. Scheme of the experimental process.

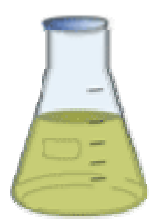




\subsection{Gas chromatography}

Fatty acid methyl esters was quantified using a gas chromatograph Trace GC-Ultra connected to an ZB-WAX capillary column (Length- $60 \mathrm{~m}$, Diameter- $0.25 \mathrm{~mm}$, Film thickness$0.25 \mu \mathrm{m})$, from Agilent Technologies with helium as carrier gas, at constant flow of $1 \mathrm{~mL} / \mathrm{min}$. The temperature program of each run was started at $50{ }^{\circ} \mathrm{C}$ for $2 \mathrm{~min}$ and raised to $240{ }^{\circ} \mathrm{C}$ at a rate of $10{ }^{\circ} \mathrm{C} / \mathrm{min}$ and maintained for $30 \mathrm{~min}$. The injector was set up for $250{ }^{\circ} \mathrm{C}$ and the FID detector at $240{ }^{\circ} \mathrm{C}$.

The analysis was carried out by diluting the biodiesel (diluted to $1 \mu \mathrm{L}$ by adding $1000 \mu \mathrm{L}$ of methanol), and $1 \mu \mathrm{L}$ of this solution was injected through the column. Methyl heptadecanoate was used as an internal standard.

\subsection{Acidity value}

The acidity value was determined according to UNE EN 14104 (2003) to quantify the amount of acid present in the biodiesel. It is measured as the quantity of base necessary to neutralize the acidic components in the sample. For this determination, a sample of $8 \mathrm{~g}$ was collected in an Erlenmeyer flask. A mixture of diethyl-ether and ethanol (1:1) and $0.15 \mathrm{~mL}$ of indicator (Phenolphthalein) were added to the sample. Then, that sample was titrated against a solution of $\mathrm{KOH} 0.1 \mathrm{M}$. Finally, the acidity value was calculated using eq. (1).

$$
A V\left(\frac{m_{\mathrm{KOH}}}{g_{\text {sample }}}\right)=\frac{V_{\mathrm{KOH}} \cdot M_{\mathrm{KOH}} \cdot P M_{\mathrm{KOH}}}{g_{\text {sample }}}
$$

where $\mathrm{V}_{\mathrm{KOH}}$ is the volumen of $\mathrm{KOH}$ used in the titration expressed in $\mathrm{mL}, \mathrm{M}_{\mathrm{KOH}}$ is the molar concentration of the $\mathrm{KOH}$ solutions in $\mathrm{mol} / \mathrm{L}, \mathrm{PM}_{\mathrm{KOH}}$ is the molecular weight of the $\mathrm{KOH}$ and $\mathrm{g}_{\text {sample }}$ is the amount of sample used in the titration.

The acidity value allow to determine the reaction conversion as follows:

$$
\text { Conversion }(\%)=\frac{A V_{0}-A V_{1}}{A V_{0}}
$$

where $A V_{0}$ is the acidity value of waste frying oil and $A V_{1}$ is the acidity value of obtained biodiesel.

\section{Results and discussions}

\subsection{Effect of catalyst amount}

The amount of catalyst is a critical factor to be determined in the transesterification reaction. Two different amounts of sodium hydroxide ( 0.5 and $1 \%$ wt.) were tested. The reaction conditions were $60 \mathrm{~min}$ and $30{ }^{\circ} \mathrm{C}$. Figure 2 shows the effect of amount of sodium hydroxide on reaction conversion. It is observed that amount of $0.5 \% \mathrm{wt}$. was enough to carry out the reaction, with a conversion of $69 \%$. It has been reported that an excess of catalyst leads to saponification resulting in lower biodiesel yield and quality (Gude and Grant, 2013).

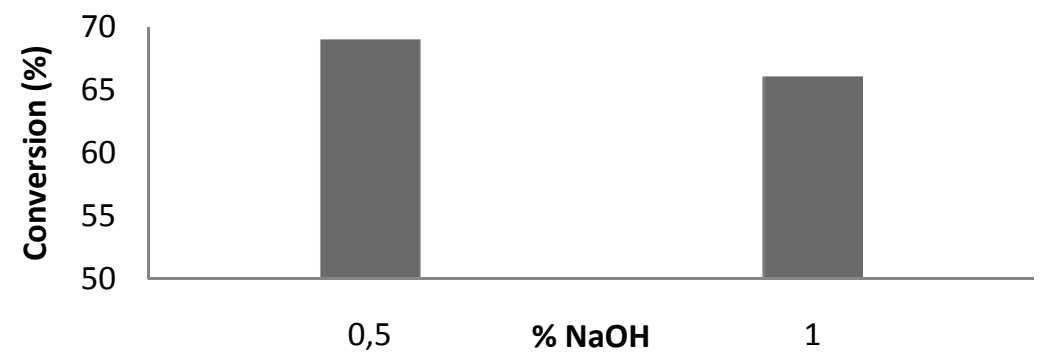

Figure 2. Effect of catalyst on trasesterification. 


\subsection{Effect of reaction time}

Reaction time is one of the most important parameters to be optimized since the reaction completion depends on it. Thus, three reactions times were analysed from 30 to $90 \mathrm{~min}$ at $30 \mathrm{~min}$ increments up. The reaction conditions of three experiences were: $0.5 \%$ wt. of $\mathrm{NaOH}$ and $30{ }^{\circ} \mathrm{C}$. Figure 3 shows the influence on reaction time on reaction conversion. A reaction time of $60 \mathrm{~min}$ presents the better results.

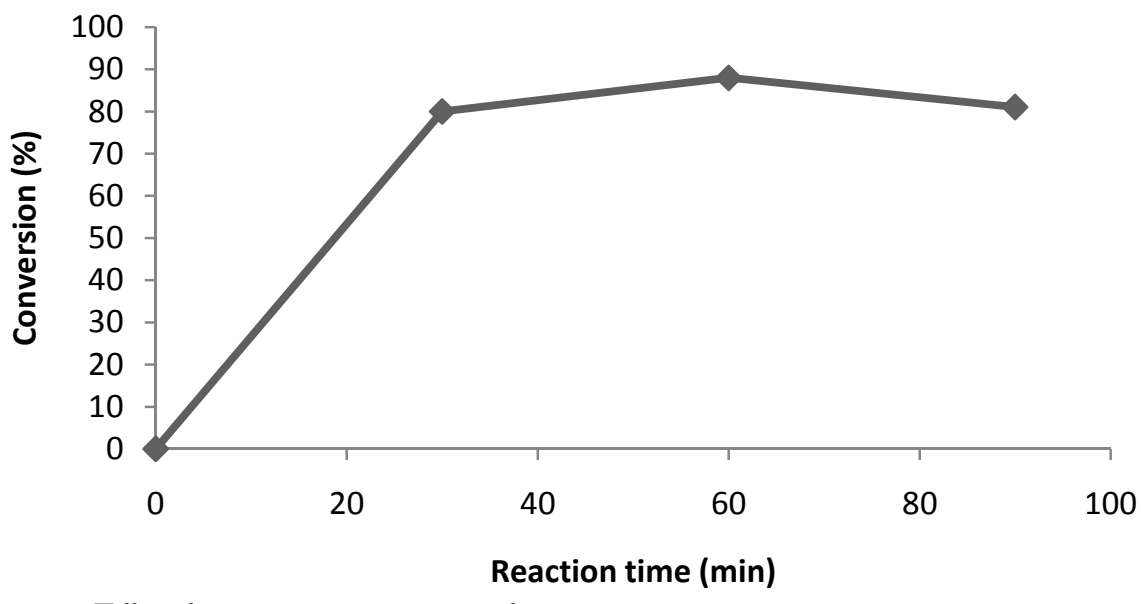

Figure 3. Effect of reaction time on transesterification.

Figure 4 shows the GC chromatogram for the test with 60 min of reaction time and the relative amount of each long chain fatty acid methyl esters for the three test is collected in table 1 . These results confirm near complete transesterification of triglycerides into biodiesel.

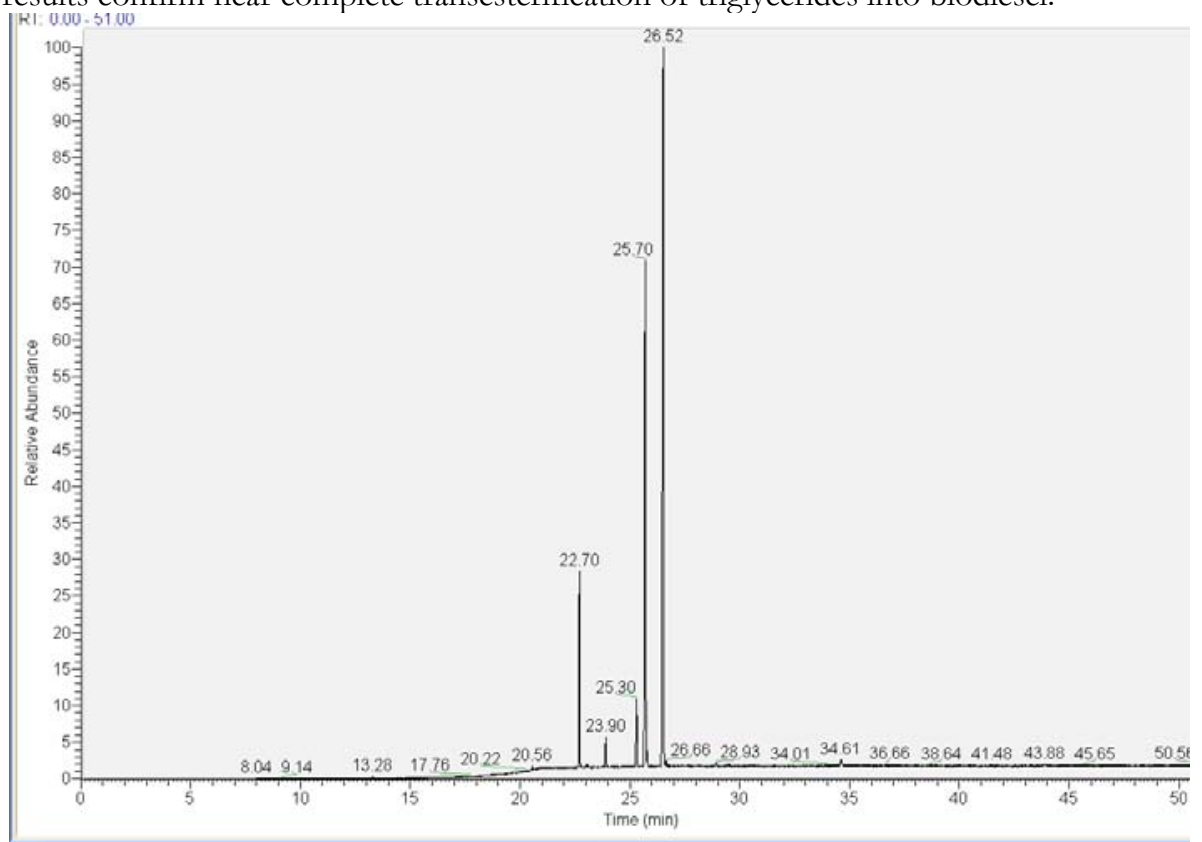

Figure 4. GC chromatogram. 
Table 1. Fatty acid methyl esters composition.

\begin{tabular}{llll}
\hline Methyl ester & $\begin{array}{l}\text { Test } 30 \\
\% \text { in sample }\end{array}$ & $\begin{array}{l}\text { Test } 60 \\
\% \text { in sample }\end{array}$ & $\begin{array}{l}\text { Test } 90 \\
\% \text { in sample }\end{array}$ \\
\hline Caprylic acid, ME. & 0.1 & 0.1 & 0.1 \\
Tetradecanoic acid, ME. & 0.1 & 0.1 & 0.1 \\
Palmitic acid, ME. & 8.2 & 8.2 & 8.3 \\
Stearic acid, ME. & 3.8 & 3.9 & 4.1 \\
Oleic acid, ME. & 32.5 & 32.7 & 32.5 \\
Linoleic acid, ME. & 54.2 & 54.0 & 53.8 \\
Eicosanoic acid, ME. & 0.3 & 0.3 & 0.2 \\
cis 11-eicosanoic acid, ME. & 0.2 & 0.2 & 0.2 \\
Behenic acid, ME. & 0.7 & 0.6 & 0.7 \\
\hline
\end{tabular}

\subsection{Effect of reaction temperature}

To investigate the influence on reaction initial reaction temperature, three experiences were carried out at 20,30 and $40{ }^{\circ} \mathrm{C}$ All the tests were done under the same conditions: $0.5 \%$ wt. of sodium hydroxide and $60 \mathrm{~min}$ of reaction time. Figure 5 shows the obtained conversion in each test. Higher conversions were obtained in three cases, although it was observed that the conversion decreases when the temperature is higher than $30^{\circ} \mathrm{C}$. Some researches have observed that higher reaction temperatures result in overall decrease in the ultrasound based chemical reaction effect (Ji et al., 2006). The increased of reaction temperature also decreased of viscosity of waste frying oil, increased of cavitation events and the rate of emulsion formation, thus consequently increased the biodiesel formation. However, when the experience was done at ambient temperature $\left(20^{\circ} \mathrm{C}\right)$ the conversion was lower than $30^{\circ} \mathrm{C}$. This finding can be due to the lower temperature causes a higher viscosity, which difficult the formation of cavitation bubbles, resulting a reduction on ultrasound efficiency.

One advantage of the ultrasound-assisted transesterification is that the reaction can be effective even at low reaction temperatures, avoiding the methanol evaporation. Then, the optimum temperature of this research was $30^{\circ} \mathrm{C}$, this value had also been reported by (Yu et al., 2006).

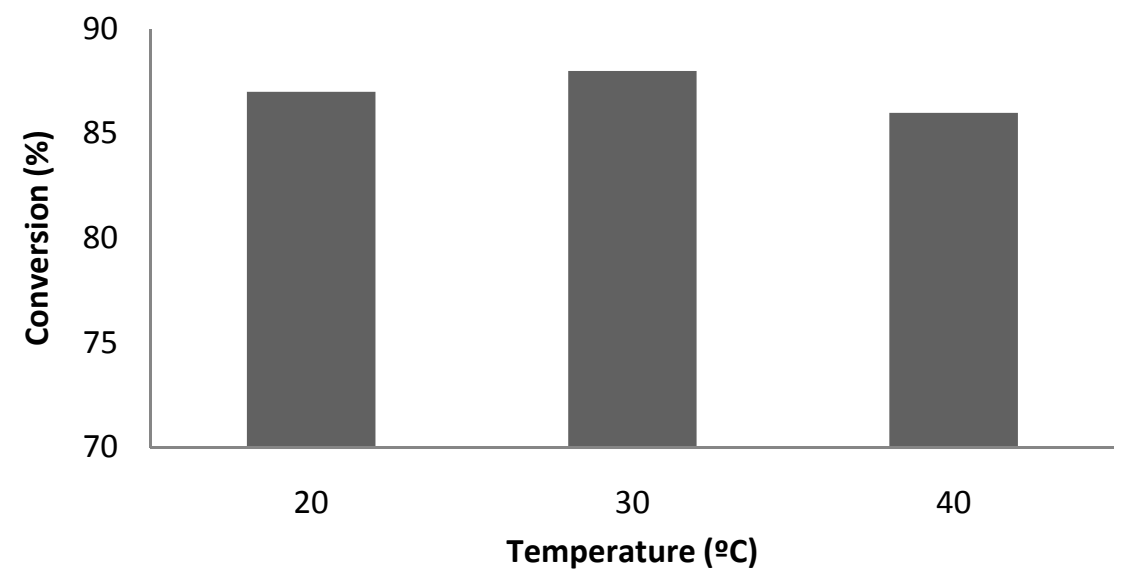

Figure 5. Effect of reaction temperature on transesterification.

\section{Conclusions}

This research investigated the use of ultrasound irradiation on transesterification of waste frying oil and the variables of the process. These variables include the influence of catalyst 
amount, reaction time and reaction temperature. The obtained results show that the transesterification reaction can be completed in $60 \mathrm{~min}$ and $30^{\circ} \mathrm{C}$ with $0.5 \%$ wt. of sodium hydroxide and methanol to oil molar ratio 6:1. Then, ultrasonic-assisted transesterification of the waste frying oil seems a good alternative for the production of biodiesel, since high methyl ester yield and fast reaction rate can be obtained even if reaction temperature is relatively low.

\section{References}

Dorado, M.P., E. Ballesteros, J.M. Arnal, J. Gómez, and F.J. López, 2003. Exhaust emissions from a diesel engine fuelled with transesterified waste olive oil. Fuel 82: 1311-1315.

Ehimen, E.A., Z. Sun, G.C. Carrington, 2012. Use of ultrasound and co-solvents to improve the in-situ transesterification of microalgae biomass. Procedia Environmental Sciences 15: 47-55.

Felizardo, P., M.J. Neiva Correia, I. Raposo, J.F. Mendes, R. Berkemeier, and J. Moura Bordado, 2006. Production of biodiesel from waste frying oils. Waste Management 26: 487-494.

Fukuda, H., A. Kondo, and H. Noda, 2001. Biodiesel fuel production by transesterification of oils. Journal of Bioscience and Bioengineering 92: 405-416

Gude, V.G., and G.E. Grant, 2013. Biodiesel from waste cooking oils via direct sonication. Applied Energy 109: 135-144.

Ji, J., J. Wang, Y. Li, Y. Yu, Z. Xu, 2006. Preparation of biodiesel with the help of ultrasonic and hydrodynamic cavitation. Ultrasonics 44, 411-414.

Maceiras, R., M. Vega, C. Costa, P. Ramos, and M.C. Márquez, 2009. Effect of methanol content on enzymatic production of biodiesel from waste frying oil. Fuel 88, 2130-2134.

Mittelbach, M., and P. Tritthart, 1988. Diesel fuel derived from vegetable oils, III. Emission tests using methyl esters of used frying oil. Journal of American Oil Chemistry \& Society 65: 1185-1187.

Phan, A.N., T.M. Phan, 2008. Biodiesel production from waste cooking oils. Fuel 87: 3490-3496.

Refaat, A.A., Attia N.K., Sibak H.A., El Sheltawy S.T., ElDiwani G.I., 2008. Production optimisation and quality assessment of biodiesel from waste vegetable oil. International Journal of Environmental Science Technology 5: 75-82.

Thanh, L.T., K. Okitsu, Y. Sadanaga, N. Takenaka, Y. Maeda, and H. Bandow, 2010. Ultrasound assisted production of biodiesel fuel from vegetable oils in a small scale circulation process. Bioresource Technology 101, 639-645.

Ulusoy, Y., Y. Tekin, M. Cetinkaya, and F. Karaosmanoglu, 2004. The engine tests of biodiesel from used frying oil. Energy Sources 26: 927-932.

Schafer, A., 1998. Vegetable oil fatty acid methyl esters as alternative diesel fuels for commercial vehicle engines, p. 29- 46. In Martini, N. and Schell, J. S. (ed.), Plant oils as fuels. Springer-Verlag, Heidelberg.

Stavarache C., M. Vinatoru, R. Nishimura, and Y. Maeda, 2005. Fatty acids methyl esters from vegetable oils by means of ultrasonic energy. Ultrasonics Sonochemistry 12: 367-372.

Wijana, S., S.A. Mustaniroh, and I. Wahyuningrum, 2005. Utilization of used frying oil in the making of soap: effect of saponification time and a dextrin concentration. Jurnal Teknologi Pertanian 6: 193-202.

Yu D., L. Tian, H. Wu, S. Wang, Y. Wang, D. Ma, and X. Fang, 2010. Ultrasonic irradiation with vibration for biodiesel production from soybean oil by Novozym 435. Process Biochemistry 45: 519-525.

Zaher, F., 2003. Utilization of used frying oil as diesel engine fuel. Energy Sources 25: 819-826. 